\title{
Cursinhos Preparatórios para Residência Médica: Reflexões sobre Possíveis Causas e Consequências*
}

\author{
Preparatory Courses for Medical Residency: \\ Reflections on Possible Causes and \\ Consequences
}

Pedro Tadao Hamamoto Filho Angélica Maria Bicudo Zeferino ${ }^{I I}$

\section{PALAVRAS-CHAVE: \\ - Educação Médica. \\ - Residência Médica. \\ - Cursinhos Preparatórios. \\ - Ensino Superior.}

\section{KEYWORDS:}

- Medical Education.

- Residency.

- Preparatory Courses.

- Higher Education.

Recebido em: 04/10/2010

Reencaminhado em: 05/07/2011

Aprovado em: 25/09/2011

REVISTA BRASILEIRA DE EDUCAÇÃO MÉDICA $550 \frac{145: 550.556 ; 2011}{35}$
* Trabalho realizado na Faculdade de Medicina de Botucatu/Unesp e na Faculdade de Ciências Médicas/Unicamp.

IUniversidade Estadual Paulista "Júlio de Mesquita Filho", Botucatu, São Paulo, Brasil.

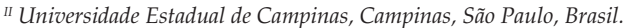

RESUMO

O ensino superior brasileiro tem sofrido mudanças significativas nas últimas décadas após a reforma universitária e a ampliação do setor privado. O número de escolas médicas é crescente, porém não tem sido acompanhado do aumento do número de vagas de residência médica. A competição acirrada por vagas de residência médica pode levar os estudantes a buscar auxílios para estudo, como os cursinhos preparatórios. A presença de estudantes nestes cursinhos pode influenciar negativamente o modo de aprendizagem dos médicos em formação, por estes se submeterem a normas de condutas e rotinas de estudo enrijecedoras. Entendendo os cursinhos como reflexo do desequilíbrio de políticas educacionais e de saúde, aponta-se a necessidade de políticas de formação profissional em saúde embasadas em necessidades sociais.

\section{ABSTRACT}

Brazilian higher education has undergone significant changes in recent years, following the university reform and the expansion of the private sector. There are a growing number of medical schools, yet the number of medical residency places has not increased accordingly. The stiff competition for residency places can lead students to seek study support, such as preparatory courses. The presence of students in these courses can have a negative influence on the learning methods of trainee doctors, as the latter are subjected to restrictive study routines and standards. Understanding these courses as a reflection of the imbalance of health and education policies, there is an identifiable need for health education policies based on social needs. 


\section{INTRODUÇÃO}

O presente estudo discute as razões da procura de estudantes de Medicina por cursinhos preparatórios $(\mathrm{CP})$ para concursos de residência médica, contextualizando a discussão no cenário do ensino superior brasileiro, em geral, e da formação médica, em particular. Além disso, discutem-se possíveis influências desses CP no comportamento e no aprendizado dos estudantes.

Desde a reforma universitária de 1968, a educação brasileira tem vivido um forte crescimento no setor privado. Para diversos autores, isto se deve a uma "não política" do Estado na área educacional, deixando ao capital privado a responsabilidade pelo avanço e massificação do ensino superior no País.

O ensino médico não ficou imune ao processo. Constatou-se um aumento expressivo do número de escolas médicas privadas no Brasil, especialmente a partir da década de 1990. Este crescimento, no entanto, não foi acompanhado proporcionalmente de um aumento do número de vagas de residência médica (RM). A combinação desses fatos, inevitavelmente, levou a um significativo aumento da concorrência por vagas de RM, o que constituiu um ambiente propício à proliferação de $\mathrm{CP}$.

$\mathrm{O}$ acesso aos programas de RM, por outro lado (e apesar das recentes modificações), ainda privilegia a verificação do conhecimento teórico, contribuindo para a procura por $\mathrm{CP}$. Este processo, portanto, necessita de maior reflexão, especialmente em virtude da constatação do distanciamento dos estudantes das atividades da prática clínica, privilegiando o estudo teórico, que, por sua vez, baseia-se cada vez mais em apostilas e materiais didáticos entregues pelos CP em detrimento dos livros e artigos científicos.

Essa nova forma de "aprender medicina" - ou, antes, de memorizar respostas para uma prova - certamente não condiz com as necessidades de uma formação crítica e reflexiva, ocasionando danos à formação médica.

\section{O ensino superior no Brasil}

Até meados do século XX, o ensino superior no País era privilégio da elite social. Havia poucas instituições, com poucas vagas e poucos cursos, voltados para profissões tradicionais. Já no período de 1945-1965, as matrículas em instituições públicas de ensino superior passaram de 21 mil para $182 \mathrm{mil}$. Na década de 1960, houve intenso movimento por uma reforma no setor, traduzindo as aspirações de cientistas com formação no exterior que desejavam fazer da universidade brasileira um local de produção de conhecimento ${ }^{1}$. Paralelamente, havia grande pressão social por uma expansão do ensino universitário que atendesse à demanda do crescimento populacional e que solucionasse o problema dos "excedentes", que eram aprovados para o ingresso, mas não estudavam por falta de vagas disponíveis².

Após o golpe militar de 1964, o governo viu-se pressionado a reformular a política para o ensino superior. A ideologia da nova política se pautava na necessidade de a educação universitária ter objetivos práticos dirigidos ao desenvolvimento nacional. A escassez de recursos financeiros para o devido aumento de vagas trouxe o princípio de "expansão com contenção": oferecimento de mais vagas com a manutenção da infraestrutura e dos recursos humanos disponíveis. Embora os documentos oficiais não citassem a participação do setor privado - que, à época, se limitava às instituições confessionais e a raros institutos isolados - no processo de expansão, a ênfase na falta de recursos permitiu, posteriormente, que se evocasse a complementaridade de instituições privadas na expansão ${ }^{1}$. Registre-se que, a despeito da falta de recursos para maior expansão de vagas, implementou-se um sistema de fomento à pesquisa e à pós-graduação que permitiu uma sofisticação acadêmica às instituições federais.

A expansão aquém das necessidades sociais abriu campo para o desenvolvimento do setor privado na educação superior. A posteriori, houve menções claras à participação privada na expansão, cabendo-lhe assegurar vagas a alunos com baixas condições econômicas ${ }^{1}$.

O País viu, então, uma escalada na proliferação de instituições privadas de ensino superior. Outrora minoria, passaram a deter a maioria das matrículas. As mudanças de legislação permitiram-lhes, ainda, a organização em centros universitários e universidades a partir da fusão de institutos isolados. Estas instituições, todavia, sempre enfrentaram dificuldades em implementar a esperada política universitária de articulação entre ensino, pesquisa e extensão. Além disso, ainda carecem do desenvolvimento de carreira docente e dificilmente conseguem institucionalizar a prática de pesquisa e pós-graduação stricto sensu. Organizadas a partir de uma tradição existencial de centros de ensino, criam artificialismos acadêmicos para atender à legislação ${ }^{3}$. Ocorre que, gozando do prestígio de centros universitários e universidades para a abertura de cursos e vagas, essas instituições puderam formalizar um verdadeiro mercado empresarial de ensino superior, que passou de "mercado de demanda" para um "mercado de oferta" de vagas; se antes muitos candidatos disputavam poucas vagas no ensino superior, hoje sobram vagas ${ }^{2}$. Regulada pelo mercado, essa expansão de instituições e vagas de ensino superior não levou em consideração as necessidades sociais ${ }^{4,5}$.

A partir do fim do século XX, o Estado foi se mostrando inoperante em regular e prover bens à sociedade, vendo-se cercado de falta de credibilidade e reconfigurando suas rela- 
ções com a sociedade. Em suas reformas, desfaz-se de responsabilidades e as transfere à própria sociedade e ao mercado. A educação não passou imune por este processo, e as instituições educacionais, ainda que não alheias aos processos de transformação social, não têm conseguido lidar com eles da melhor forma nem têm respondido aos desafios que lhes são lançados ${ }^{6}$. Ao ensino superior brasileiro, nas últimas quatro décadas, parece ter faltado um plano estratégico voltado à qualificação do sistema educacional, com vistas a iniciativas de redução de desigualdades regionais, à capacitação docente e melhor formação profissional, de onde se pode deduzir que o sistema de graduação foi, em grande parte, resultado de uma não política ${ }^{3}$.

\section{As Escolas Médicas no Brasil}

A medicina brasileira seguiu a tendência das outras profissões em termos de aumento de vagas e instituições de ensino. Em 1960, eram 26 escolas médicas, que formavam, em média, 1.200 profissionais. Já em 1973, eram 73 escolas, formando 3 mil médicos ${ }^{7}$. Na discussão deste aumento de instituições de ensino médico, devem-se incluir os movimentos sociais e urbanos que impunham aumento de gastos com assistência médica e hospitalar. Dados foram mobilizados para também pressionar o aumento de escolas médicas diante do quadro de milhares de municípios sem médicos, reduzida proporção médicos/habitantes e maus indicadores de saúde ${ }^{8}$.

Os resultados desse crescimento foram mazelas como corpo docente desqualificado, com pouca ou nenhuma atividade de pesquisa; professores convidados itinerantes; e falta de cenários de prática para os estudantes, com cursos eminentemente teóricos. Nas décadas de 1960 e 1970, mudanças e inovações curriculares foram apresentadas como respostas das instituições públicas às deficiências da formação médica da época ${ }^{7}$.

Com a chamada "crise da medicina" no fim da década de 1980, não obstante a declarada priorização do setor saúde pelas esferas do governo, o desenvolvimento de recursos humanos continuou à margem do processo, e o setor educacional permaneceu desvinculado da reorganização do sistema, dos serviços e das políticas de saúde. Desse modo, a grande maioria das novas escolas incorporou o modelo biomédico, com uma visão reducionista dos programas educacionais, enfatizando o modelo biomédico centrado na doença e no hospital, e reservou pequeno espaço para as dimensões psicossocial e econômica da saúde ${ }^{9}$.

Desde então, presenciou-se um aumento expressivo do número de escolas médicas, principalmente a partir da década de 1990, quando houve uma aceleração ainda maior do pro- cesso. Este aumento, no entanto, mais uma vez não respondeu às necessidades sociais. Esta lógica naturalmente seguiu a lógica do mercado: "oferta de vagas" onde há procura. Também na medicina, faltou coordenação entre instrumentos de formação e necessidades da população ${ }^{10}$.

Hoje, o Brasil tem mais faculdades de Medicina que os Estados Unidos e a China. Dados do Ministério da Educação mostram haver hoje 183 cursos de Medicina em atividade no País $^{11}$. Por outro lado, felizmente, o Ministério da Educação tem buscado recentemente medidas que reduzam os danos instalados. A perspectiva de interromper a proliferação de escolas médicas tem sido um fator determinante para que entidades se articulem com o objetivo de avaliar o ensino médico brasileiro, criar mecanismos de avaliação das escolas e propor medidas que qualifiquem a formação médica ${ }^{12-14}$.

\section{A Residência Médica}

Em 1848, nos Estados Unidos, iniciou-se uma discussão sobre um sistema de instrução de médicos baseado na utilização da rede hospitalar para o ensino. Era a RM, assim nomeada pelo fato de os médicos terem de morar nas instituições para estarem à disposição do serviço em tempo integral ${ }^{15}$.

No Brasil, os primeiros programas de RM surgiram na década de 1940, no Hospital das Clínicas da Faculdade de Medicina da USP e no Hospital dos Servidores do Estado do Rio de Janeiro. Em 1977, o Decreto 80.281 criou a Comissão Nacional de Residência Médica (CNRM), que se tornou importante para a regulamentação dessa modalidade de pós-graduação como cursos de especialização baseados no treinamento em serviço para médicos (Lei 6.932/1981).

Reconhece-se a RM com a dupla função de complementar a formação do médico (haja vista a não terminalidade do curso de graduação em Medicina) e oferecer a especialização como possibilidade de melhor inserção no mercado de trabalho. Para os médicos recém-formados que ingressam na RM, esta representa um momento especial de sua formação, no qual combinam os conhecimentos teóricos com a experiência clínica que adquirem como profissionais. Esta experiência é fundamental, pois o profissional passa a se apropriar dos doentes, e não mais das doenças. Também neste período de sua formação, com aprendizado em serviço, o médico passa a construir a ética de sua relação profissional com os pacientes $^{16}$.

Apesar da importância da RM para o desenvolvimento médico profissional e para a prestação de serviços, análises das políticas oficiais para o setor saúde/educação mostraram que ela não foi alvo de preocupação e planejamento. Assim, as tendências de mercado interferiram diretamente na demanda 
dos futuros residentes por determinadas especialidades. Portanto, de certa forma, os rumos da RM foram traçados à mercê do que ocorria com a educação médica e com as políticas de saúde. As necessidades das instituições que ofereciam os programas e os interesses das corporações médicas definiram as características dos programas de $\mathrm{RM}^{16}$.

Em acréscimo à discussão, a oferta de vagas dos programas de RM não acompanhou o aumento do número de escolas médicas e de médicos formados, colocando o País na berlinda de um contingente crescente de egressos que buscam, em serviços públicos da atenção primária à saúde e de pronto atendimento, oportunidades de trabalho temporárias, até que consigam uma vaga de RM. Essa lógica, evidentemente, tem contribuído para a precarização do sistema de saúde. Levantamentos do Conselho Federal de Medicina mostram que, em quase uma década, o contingente de médicos que afirma ter feito residência médica diminuiu de 74\% em 1996 para pouco mais de $60 \%$ em 2004. Mostram também aumento em atividades plantonistas, redução do número de médicos que atuam em consultórios e no setor privado, e que o PSF tem sido importante local de inserção profissional. Estes levantamentos evidenciam uma tendência de criar uma massa de médicos sem acesso à RM, delineando-se uma espécie de divisão maléfica entre médicos qualificados e não qualificados ${ }^{17,18}$.

As mudanças da prática médica (e mesmo do perfil de morbimortalidade do País) e a necessidade de qualificar o Sistema Único de Saúde (SUS), cuja meta é atender de forma integral a totalidade da população, têm forçado os gestores a discutir o direcionamento de bolsas de RM para novos programas, como Saúde da Família, Mastologia, Medicina do Trauma e Medicina Intensiva. As restrições econômicas, contudo, novamente se interpõem à formulação de novas políticas. Desta forma, fica cada vez mais acirrada a disputa por vagas de RM, sobretudo nas especialidades mais procuradas pelos egressos das escolas médicas. De forma bastante conspícua, Nunes elencou os problemas da RM em quatro aspectos: avaliação, necessidade, acesso e financiamento ${ }^{15}$.

\section{Concursos para Acesso à Residência Médica}

A CNRM estipulou normas para os processos seletivos, tentando evitar privilégios aos candidatos oriundos da escola que oferece as vagas. A Resolução 01/2001 estabeleceu um peso mínimo de $90 \%$ para provas objetivas, com igual número de questões divididas entre as cinco áreas básicas (Clínica Médica, Ginecologia e Obstetrícia, Cirurgia, Medicina Preventiva e Pediatria) e 10\% para prova oral, entrevista ou arguição curricular. Com essa pontuação, objetivava-se dificultar eventuais favorecimentos e garantir o princípio de justiça e direitos iguais a todos os brasileiros ${ }^{15,19}$. Acredita-se que esta distribuição de pesos tenha afastado os estudantes dos estágios práticos, pois eles se voltaram para o conhecimento teórico em detrimento da prática clínica ${ }^{15}$.

O modelo de prova que prioriza o conhecimento teórico, aplicado na maioria das instituições do País, afasta os estudantes das atividades clínicas da prática profissional durante o internato, pois estes preferem se dedicar ao estudo teórico do conteúdo abordado nas provas para RM em detrimento das habilidades e competências a serem adquiridas para a plena formação do médico ${ }^{19,20}$. Este fato levou a CNRM a propor, em 2004, uma alteração no processo seletivo, incluindo uma prova prática com peso de $40 \%$, ficando a prova escrita com peso de $50 \%$ e a entrevista com análise curricular com $10 \%{ }^{21}$. Com esta medida, tentou-se resgatar a valorização do treinamento prático dos estudantes de Medicina durante o internato ${ }^{22}$.

\section{Cursinhos Preparatórios}

A competição acirrada por vagas de RM e os modelos de prova que priorizam o conhecimento teórico levam os estudantes a buscar alternativas para ingressar nos programas de RM, como os cursinhos preparatórios (CP).

Os CP utilizam estratégias de ensino similares às dos cursinhos pré-vestibulares, com aulas semanais, organização do curso em módulos, revisões próximas das provas, resolução de questões, etc. Dispõem de material didático bastante objetivo, focado na resolução de questões de provas, com estética atraente, leitura simples e discussão de questões de exames anteriores de diversas instituições. Têm infraestrutura ampla, bons auditórios e disponibilizam aulas presenciais e transmitidas via internet. Realizam simulados e, mais recentemente, treinamentos para as provas práticas. Em geral, as aulas são ministradas semanalmente, com carga horária de quatro a cinco horas por semana, no período noturno ou em finais de semana. O preço das mensalidades gira em torno de $\mathrm{R} \$ 200,00$ a $\mathrm{R} \$ 400,00$. O corpo docente geralmente é composto por profissionais de tradicionais e renomadas faculdades de Medicina. Dos CP consultados, o primeiro surgiu em 1996. Os demais em 2000, 2003, 2004 e 2005. Um deles não fornece informação sobre o início de suas atividades ${ }^{23-28}$.

Tanto tem se fortalecido esse tipo de mercado entre os candidatos a vagas de RM que algumas empresas oferecem serviço especializado em "recursos judiciais" para contestações de concursos e questões de provas. Frequentemente, obtêm parecer favorável das instâncias judiciais às quais recorrem ${ }^{23}$.

Todos os CP utilizam propagandas e atraentes diferenciais para garantir eficácia nas aprovações. Alguns deles oferecem vantagens como a possibilidade de optar entre módulos inten- 
sivos ou extensivos, aulas presenciais ou a distância e entrega de iPhones ou notebooks como material de ensino ${ }^{23-28}$.

Chehuen Neto et al. ${ }^{29}$ conduziram estudo em que avaliaram expectativas e opiniões de alunos do sétimo ao nono período sobre os CP. Quando perguntados sobre se já haviam utilizado material de $\mathrm{CP}$ para estudo, observou-se aumento progressivo de respostas afirmativas com o avançar dos períodos. Os motivos para isto foram as provas de faculdade e uso do material como método de estudo (decrescentes com o avançar dos períodos) e preparação para RM (crescente com o avançar dos períodos). Com relação a motivos para futuramente se matricularem em CP, foram elencados: preparação com o material e aulas, o fato de o compromisso semanal motivá-los a estudar sempre, atualização e revisão para a prova, e porque a maioria dos estudantes faz (este motivo, decrescente com o avançar dos períodos). Para estes autores, essa iniciativa privada se contrapõe ao nobre modelo universitário em que os estudantes devem ser estimulados a buscar o próprio conhecimento, pois os $\mathrm{CP}$ prezam a memorização em detrimento do raciocínio clínico ${ }^{29}$.

No estudo de Leite et al..$^{22}$, avaliou-se a efetividade dos CP. Para tanto, compararam candidatos que estudaram em CP ou não no desemepnho na prova do concurso para RM no Hospital Universitário da Universidade Federal de Juiz de Fora, em 2006. Dos candidatos inscritos e que aderiram ao estudo, mais de $70 \%$ tinham frequentado CP num período médio de 11 meses. Não se observaram diferenças nas aprovações entre os que frequentaram CP ou não. Contudo, o desempenho dos que frequentaram foi melhor: quatro pontos a mais do que os que não se prepararam em CP. Num modelo de concurso em que $90 \%$ da nota provêm da prova teórica, a preparação em CP seria mais eficaz ${ }^{22}$.

\section{Impacto dos CP na Formação Médica}

$\mathrm{O}$ que se tem presenciado entre alguns estudantes de muitas escolas médicas é um distanciamento crescente das atividades regulares do internato, com maior preocupação em cumprir os cronogramas propostos pelos CP. Assim, deixam de estudar com base nos casos clínicos que atendem e se voltam à leitura de apostilas e resolução de questões.

Outra constatação é a de que os materiais de estudo deixam de ser os clássicos livros de medicina, bem como artigos, diretrizes e consensos, passando a ser as apostilas dos CP. A preferência por esse material é óbvia: informação bastante concisa, objetiva, direcionada e com forte apelo visual, além da articulação com questões de prova com assuntos correlatos ao em estudo. A lógica subjacente é reter a maior quantidade de informações para acertar o maior número de questões nas provas. A crítica científica é relegada a segundo plano.
Além disso, esses CP estabelecem normas de conduta a serem seguidas para se atingir o objetivo de ser aprovado na RM. Cria-se um ambiente hostil, em que impera a competitividade e se destaca a necessidade de ser o melhor. O professor deixa de ser um propositor, um facilitador da aprendizagem, e torna-se o vendedor das verdades absolutas que serão cobradas em testes de múltipla escolha. $\mathrm{O}$ hábito de estudar se transforma em um processo de adoecimento coletivo, quando deveria ser prazeroso e visto como ampliador de possibilidades de estratégias de vida.

Luz e Silva ${ }^{30}$, tratando dos cursinhos destinados a concursos públicos, caracterizam bem as estratégias "vitoriosas e perfeitas" prescritas aos candidatos: ter um número $x$ de horas de estudo por dia/semana/mês/ano; comportamentos certos para estudar, com orientação de postura corporal e ambiente de estudo; prazos enrijecidos e generalizados para cumprir metas de estudo; mecanismos mnemônicos de aprendizado; abstinências e renúncias sociais imprescindíveis; o que comer, o que não comer; que esporte/atividade física praticar ou não... por fim, estar fora deste estereótipo acarretaria fracasso. Nesse contexto, não raro, indivíduos desenvolvem inquietações intrapsíquicas e sofrimento mental ao constatarem a limitação em cumprir à risca as prescrições pelas quais têm empenhado tempo e dinheiro ${ }^{30}$.

Esses mesmos autores defendem um estudar criativo, inventivo, satisfatório e heterogêneo. Este estudar permitiria o surgimento de indivíduos mais ativos, apaixonados pela criação e provocadores de metamorfoses ${ }^{30}$. Acredita-se que estes traços do perfil dos médicos são o que a sociedade precisa - médicos que vislumbrem horizontes amplos e que saibam fugir dos scripts que perpetuam os danos e agravos à saúde dos indivíduos e da coletividade. Neste sentido, mecanismos enrijecedores e pré-formatados adotados pelos CP somente prejudicam a formação médica.

Outro aspecto a discutir é a desigualdade socioeconômica que se reflete nos concursos para RM. No estudo de Leite et al. ${ }^{22}$, os candidatos com condições financeiras de financiar os cursinhos levariam vantagem no desempenho das provas. Isto corrobora um dado do estudo de Chehuen Neto et al..$^{29}$ : o principal motivo para não haver intenção de se matricular em $\mathrm{CP}$ futuramente é a falta de condições financeiras.

\section{Desafios à Sociedade, às Escolas Médicas e ao Estado}

O Brasil tem hoje uma lógica de distribuição e inserção de médicos no mercado de trabalho que não corresponde à estruturação dos serviços de saúde e às necessidades sociais em saúde. É necessário formular e implantar uma política nacional de acesso e de formação de recursos humanos em saúde ${ }^{10,31}$. 
Para a iniciativa privada dos CP, a manutenção da lógica atual lhe permitirá franca expansão. Com o aumento do número de faculdades de Medicina sem o devido aumento de programas de RM, os índices de procura por CP devem crescer significativamente. No ciclo vicioso, os $\mathrm{CP}$ manterão sua "contribuição" para a formação de médicos estereotipados.

Modificações estruturais no sistema educacional, todavia, não são suficientes. Há que alterar modelos educacionais. As instituições de ensino superior precisam renunciar ao modelo de transmissão de informações divorciado da vida real. Os processos pedagógicos precisam recorrer ao debate e à reflexão, com docentes assumindo o papel de incitadores e facilitadores, e estudantes se responsabilizando por seu aprendizado, compreendendo o sentido e a utilidade do que aprendem, recorrendo às informações e, nesse percurso, desenvolvendo habilidades e competências necessárias a um profissional capaz de alterar seu meio.

As universidades podem superar as limitações impostas pelas celas disciplinares para a construção de integrações das áreas do conhecimento, o que propiciará benefícios tanto à formação e aos formandos quanto à produção de novos conhecimentos.

Neste sentido, formar profissionais articulando processos educacionais com o mundo de trabalho contribuirá com o desenvolvimento social. Na área da saúde, em geral, e na medicina, em particular, não podem ser concebidas modificações curriculares desvinculadas do SUS, em todos os seus níveis de assistência.

Mais que isso, é preciso também articular as mudanças de formação com mudanças do próprio mundo de trabalho. Na formação médica, trata-se também de estabelecer políticas para a RM, pensando-se estrategicamente em sua ampliação, ou seja, em programas e número de vagas de acordo com as necessidades sociais e regionais, avaliando-se processos e critérios para acesso, com especial atenção ao financiamento.

É a resolução do binômio médicos formados/mundo de trabalho médico que minimizará o problema com os CP. Neste estudo, entende-se a proliferação de CP como consequência natural do desequilíbrio na formação de médicos, tanto na graduação quanto na RM. Escolas médicas, professores e lideranças estudantis devem empreender esforços para trazer os alunos de volta às atividades clínicas do internato, ao estudo crítico com bom referencial bibliográfico, ao desenvolvimento de habilidades e competências que apenas a prática médica confere.

Posto de outra forma, seria empreender esforços para mostrar que a verdadeira medicina não se aprende com resolução de questões de prova em CP. Não seria possível di- minuir a insegurança que leva muitos estudantes a buscarem os CP se o internato oferecesse um ensino de qualidade, com processo avaliativo contínuo de formação e classificação? Esses esforços, reconhece-se, serão insuficientes caso o País não resolva seus problemas com o número de médicos formados e sua distribuição geográfica, bem como com os serviços de saúde em que esses médicos atuam, sejam serviços de atenção primária ou serviços de atenção especializada.

\section{REFERÊNCIAS}

1. Martins CB. A reforma universitária de 1968 e a abertura para o ensino superior privado no Brasil. Educ Soc Campinas. 2009;30(106):15-35.

2. Calderón AI. Universidades mercantis: a institucionalização do mercado universitário em questão. São Paulo Perspect. 2000;14(1):61-72.

3. Martins CB. O ensino superior brasileiro nos anos 90 . São Paulo Perspect. 2000;14(1):41-60.

4. Nunes E. Desafio estratégico da política pública: o ensino superior brasileiro. Rev Adm Pública. 2007;41:103-47.

5. Severino AJ. Educação e Universidade: conhecimento e construção da cidadania. Interface Comun Saúde Educ. 2002; 6(10):117-24.

6. Morgado JC. Processo de Bolonha e ensino superior globalizado. Educ Soc Campinas. 2009; 30(106):37-62.

7. Edler F, Fonseca MRF. Tendências da educação médica nas décadas de 1950-1960. Cad ABEM. 2006;2:23-4.

8. Edler F, Fonseca MRF. Proliferação das escolas médicas: aumento do número de médicos formados. Cad ABEM. 2006; 2:26-7

9. Pagliosa FL, Da Ros MA. O relatório Flexner: para o bem e para o mal. Rev Bras Educ Med. 2008;32(4):492-9.

10. Bueno RRL, Pieruccini MC. Abertura de escolas de medicina no Brasil: relatório de um cenário sombrio. Brasília: CFM; 2004.

11. Ministério da Educação [homepage]. Brasília: MEC; c2011. Sistema e-MEC. [acesso em 12 jul. 2011]. Disponível em: http:/ / emec.mec.gov.br/.

12. Associação Paulista de Medicina. Faculdades na berlinda. Rev da APM. 2009;597:10-4.

13. Associação Paulista de Medicina. Abertura indiscriminada de escolas médicas: um velho problema de todo novo dia. Rev da APM. 2009;599:22-3.

14. Amaral JL. Duzentos anos de ensino médico no Brasil. Rio de Janeiro; 2007. Doutorado [Tese] - Instituto de Medicina Social, Universidade do Estado do Rio de Janeiro.

15. Nunes MPT. Residência médica no Brasil: situação atual e perspectivas. Cad ABEM. 2004;1:30-2. 
16. Feuerwerker L. Mudanças na educação médica e residência médica no Brasil. Interface Comun Saúde Educ. 1998;2(3):51-71.

17. Carneiro MB, Gouveia VV, Coord. O Médico e o seu Trabalho: aspectos metodológicos e resultados do Brasil [livro na Internet]. Brasília: CFM; 2004 [acesso 12 jul. 2011].Disponível em: http://www.portalmedico.org.br/include/biblioteca_virtual/medico_e_seu_trabalho/trabalho.pdf

18. Machado MH,coord. Perfil dos Médicos no Brasil: análise preliminar. Rio de Janeiro: Fundação Oswaldo Cruz; 1996.

19. Goldwasser R; Fonseca V, Lobo MS, Coelho A, Santos EG, Pereira SMP. Seleção para residência médica da Universidade Federal do Rio de Janeiro: percepção dos candidatos sobre o modelo de prova. Rev Bras Educ Med. 2009; 33(1):115-21.

20. Goldwasser RS. A prova prática no processo de seleção do concurso de residência médica. Rev Bras Educ Med. 2006;30(3):115-24.

21. Brasil. Ministério da Educação. Resolução CNRM n⿳000 $00 / 2004$, de 5 de agosto de 2004. Dispõe sobre o processo de seleção pública dos candidatos aos Programas de Residência Médica. [acesso em 12 jul 2011]. Disponível em: http:/ / portal.mec.gov.br/index.php?Itemid=86\&id=1307 9\&option=com_content\&view $=$ article

22. Leite ICG, Teixeira MTB, Neves HS, Oliveira LRS,Garcia LAO,Cunha PHM. Avaliação da efetividade dos cursos preparatórios para residência médica. Rev Bras Educ Med. 2008;32(4):445-51.

23. MedCurso [homepage na Internet]. Rio de Janeiro: MedCurso; [acesso em 12 jul 2011]. Disponível em: <http:// www.medgrupo.com.br>

24. Autenticmed [homepage na Internet]. Rio de Janeiro: Autenticmed; [acesso em 12 jul 2011]. Disponível em: <http:/ / www.autenticmed.com.br>

25. PreResidência [homepage na Internet]. Belo Horizonte: Pré-Residência; c2010 [acesso em: 12 jul 2010]. Disponível em: <http:/ /www.preresidencia.com.br>
26. SJT Cursos para Residência Médica [homepage na Internet]. São Paulo: SJT; c2009 [acesso em: 12 jul 2011]. Disponível em: http:/ / www.sjtresidencia.com.br

27. Medcel Residência Médica [homepage na Internet]. São Paulo: Medcel; [acesso em: 12 jul 2011]. Disponível em: $<$ http://www.medcel.com.br>

28. Pró-R Curso de extensão médica [homepage na Internet]. Rio de Janeiro: Pró-R; c2006. [acesso em 12 jul 2011]. Disponível em: <http://www.pror.com.br>

29. Chehuen Neto JA; Sirimarco MT; Kawata Choi CM, Fava AS, Oliveira LRS, Cunha PHM. Cursinhos preparatórios para residência médica: expectativas e opiniões. Rev Bras Educ Med. 2009;33(2):205-11.

30. Luz LDP, Silva CM. O exercício de estudar em cursinhos destinados a concursos públicos. Fractal Rev Psicol. 2008;20(1):285-304.

31. Lampert JB. Tendências de mudanças na formação médica no Brasil. Rio de Janeiro; 2002. Doutorado [Tese] Escola Nacional de Saúde Pública.

\section{CONTRIBUIÇÃO DOS AUTORES}

Pedro Tadao Hamamoto Filho e Angélica Maria Bicudo Zeferino participaram igualmente na concepção,redação e revisão do presente artigo.

\section{CONFLITO DE INTERESSES}

Declarou não haver.

\section{ENDEREÇO PARA CORRESPONDÊNCIA}

Pedro Tadao Hamamoto Filho Departamento de Neurologia, Psicologia e Psiquiatria - UNESP. Distrito de Rubião Jr, s/n ${ }^{\circ}$

Botucatu - São Paulo

CEP 18618-970 - SP

E-mail: pthamamotof@hotmail.com 